\title{
Dedifferentiation of Epithelial Tumors Enhances Cytotoxicity, Survival and Expansion of Allogeneic CD8+ T Cells and Natural Killer Cells
}

\section{Anahid Jewett*, Hiromi Nakamura, Meiying Wang, Antonia Teruel, Avina Paranjpe and Marcela Romero}

The Jane and Jerry Weintraub center for reconstructive biotechnology, The Department of Oral Biology and Oral Medicine. UCLA School of Dentistry, Los Angeles, CA 90095, USA

\begin{abstract}
Our recent findings have suggested an important role for the conditioning of Natural Killer cell effector function by the cancer stem cells as well as healthy untransformed stem cells, stromal monocytes and fibroblasts in cellular differentiation and tissue regeneration. We have also reported that de-differentiation or reversion of tumor cells or healthy non-transformed cells to a less-differentiated stage activated cytotoxic function of NK cells. In this report we examined the function of allogeneic CD8 $+\mathrm{T}$ cell cytotoxic function against de-differentiated tumors to determine whether induction of cytotoxic function by de-differentiated tumors is unique to the function of NK cells or that the cytotoxic function of CD8+ T cells is similarly induced when cultured with NFKB knock down tumors. Here, we demonstrate that dedifferentiation of tumors by the inhibition of NFKB nuclear function sensitizes the tumors to allogeneic CD8+ T cell mediated cytotoxicity, and increased survival and proliferation of T cells. Moreover, increased secretion of IFN-y and GM-CSF by CD8+ T cells was observed when these cells were co-incubated with NFKB knock down tumors. More importantly, the levels of IL-6 secretion were significantly reduced in the co-cultures of CD8+ $T$ cells and NFKB knock down tumors when compared to those obtained from the co-cultures of CD8+ T cells with vector-alone transfected tumors. In addition, treatment of tumor transfectants with IFN- $y$ resulted in a decrease in the cytotoxicity and cytokine secretion by CD8+ T cells. However, the function of cytotoxic T cells remained significantly higher in the presence of IFN- $\gamma$ treated NFKB knock down tumors when compared to either untreated or IFN- $y$ treated vector alone transfected tumors. Thus, these results indicated that inhibition of NFKB function in tumors activates both NK and CTL functions, suggesting a potential role for both innate and adaptive immune effectors in differentiation and regeneration of the tissues.
\end{abstract}

Keywords: Apoptosis, CD8+ T cells, NFkB, IFN- $\gamma$, GM-CSF, Inactivation

\section{Introduction}

Cytotoxic T-Lymphocytes (CTLs) similar to NK cells mediate lysis of a variety of malignant tumors and virally infected cells, and therefore are important effectors in fight against cancer. However, depressed $\mathrm{T}$ lymphocyte proliferation and function are evident in the early stages of squamous cell carcinomas of the oral cavity [1-3]. T and NK cell cytotoxicity is also suppressed after their interaction with stem cells [46]. In contrast, interaction of NK cells with the resistant tumors did not lead to suppression of NK cell cytotoxicity [7].

Our previous studies focused on the emerging new roles of NK cells in the regulation of numbers, resistance and differentiation of cancer stem cells as well as healthy untransformed stem cells. In this regard, anergized NK cells were found to regulate survival, resistance and differentiation of interacting cancer stem cells as well as healthy untransformed stem cells. We have shown in previous studies that inhibition of NFKB either by treatment of the cells with Sulindac, a Non-Steroidal Anti-inflammatory Drugs (NSAIDs) or expression of

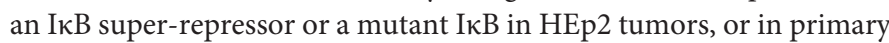
Oral Squamous Carcinoma Cells (OSCCs) or in non-tumorigenic Human Oral Keratinocytes-16B (HOK-16B) led to a significant activation of human NK cell cytotoxic function and increase in IFN- $\gamma$ secretion [8]. The increase in NK cell cytotoxicity after their co-culture with NFKB knock down tumors was paralleled with an increase in the secretion of IFN- $\gamma$ by the NK cells, and in a decrease in the secretion of IL- 6 by the tumor cells. Therefore, an overall shift in tumor profiles from an inhibitory to immune activating profile was observed in NFKB knock down tumors. Similarly, targeted deletion of IKK- $\beta$ in epidermis of mice was shown to lead to inflammatory skin manifestations [9]. Moreover, elevated levels of cytokines and chemokines was seen in the epidermis of patients and animals with Ікк $\gamma$ and Ікк $\beta$ deletions $[9,10]$. Moreover, mice with a keratinocyte-specific deletion of Ікк- $\beta$ demonstrated decreased proliferation of epidermal cells and developed TNF- $\alpha$ dependent inflammatory skin disease [9]. In contrast, in other studies in which NFKB function was blocked in dermal keratinocytes by a mutant IкB- $\alpha$ an increased proliferation and hyperplasia [11] and eventual development of cutaneous squamous cell carcinomas of skin were seen if mice were allowed to survive and reach adulthood [12,13]. Finally, targeted inhibition of NFkB function in both the intestinal epithelial cells and myeloid cells was previously shown to result in a significant decrease in size and numbers of the tumor cells [14].

Blocking TNF-a function in NFKB knock down keratinocytes resulted in the prevention of both the neoplastic transformation and the inflammatory skin disease $[9,13]$. We have also shown that NK

*Corresponding author: Anahid Jewett, The Jane and Jerry Weintraub cente for reconstructive biotechnology, Department of Oral Biology and Oral Medicine, UCLA School of Dentistry, Los Angeles, CA 90095, USA, Tel: 310-206-3970; Fax: 310-794-7109; E-mail: ajewett@ucla.edu

Received March 03, 2012; Accepted April 12, 2012; Published April 16, 2012

Citation: Jewett A, Nakamura H, Wang M, Teruel A, Paranjpe A, et al. (2012) Dedifferentiation of Epithelial Tumors Enhances Cytotoxicity, Survival and Expansion of Allogeneic CD8+ T Cells and Natural Killer Cells. J Carcinogen Mutagen S1:007. doi:10.4172/2157-2518.S1-007

Copyright: ( 2012 Jewett A, et al. This is an open-access article distributed unde the terms of the Creative Commons Attribution License, which permits unrestricted use, distribution, and reproduction in any medium, provided the original author and source are credited. 
Citation: Jewett A, Nakamura H, Wang M, Teruel A, Paranjpe A, et al. (2012) Dedifferentiation of Epithelial Tumors Enhances Cytotoxicity, Survival and Expansion of Allogeneic CD8+ T Cells and Natural Killer Cells. J Carcinogen Mutagen S1:007. doi:10.4172/2157-2518.S1-007

resistant primary oral epithelial tumors demonstrate higher nuclear $\mathrm{NF \kappa B}$ activity and secrete significant levels of Granulocyte MonocyteColony Stimulating Factor (GM-CSF), Interleukin (IL)-1 $\beta$, IL-6 and IL-8 $[15,16]$. Moreover, treatment with NSAIDs which inhibit NFkB have the ability to reverse immunosuppression induced by a tobaccospecific carcinogen [17], in addition to their well established ability to decrease oral dysplasia as well as prevention of overt cancer in transgenic animals [18].

Oral Squamous Carcinoma Stem Cells (OSCSCs), which are stem-like oral tumors and a number of different Glioblastoma cancerinitiating cells are significantly more susceptible to NK cell mediated cytotoxicity; whereas, their differentiated counterparts are significantly more resistant (manuscript submitted) [15]. In addition, human embryonic stem cells (hESCs) and human induced plueripotent stem cells (hiPSCs), as well as a number of other healthy normal stem cells such as human mesenchymal stem cells (hMSCs) and human dental pulp stem cells (hDPSCs), were found to be significantly more susceptible to allogeneic and autologous NK cell mediated cytotoxicity, and more importantly they lost susceptibility to NK cell mediated cytotoxicity and became resistant to immune cell attack upon differentiation [15]. Based on these results, we proposed that anergized NK cells may play a significant role in differentiation of the cells by providing critical signals via secreted cytokines as well as direct cell-cell contact. In this regard we reported previously that monocytes induce split anergy in NK cells by inhibiting cytotoxicity and stimulating the secretion of cytokines such as IFN- $\gamma$, TNF- $\alpha$ and IL-6 [19].

Most recent reports have also suggested a potential role for CTLs in the elimination of cancer stem cells (Kano et al. 2011; Inoda et al. 2011). However, at present it is not known whether CTLs can also target dedifferentiated tumors or those which have defects in up-regulation of important transcription factors such as NFKB which contributes to the differentiation of tumors. We demonstrate in this paper that allogeneic cytotoxic CD8+ T cells like NK cells respond similarly to the activating effect of NFKB knock down HEp2 cells as evidenced by increased survival, proliferation and functional activation of CD8+ T cells.

\section{Material and Methods}

\section{Cell lines, plasmids and reagents}

HEp2 tumor cell lines were obtained from ATCC and maintained in Dulbecco's Modified Eagle Medium (DMEM) supplemented with 10\% FBS. RPMI 1640 supplemented with 10\% FBS was used for the cultures of T cells. Recombinant IL-2 was obtained from Hoffman La Roche (Nutley, New Jersey). IFN- $\gamma$ was a generous gift from Dr. Yoichi Mizutani. TNF-a was purchased from Peprotech (Rocky Hill, $\mathrm{NJ})$. The CD8+ T cell purification kit was obtained from Miltenyi Biotech (Auburn, CA). Polyclonal anti-IFN- $\gamma$ antibodies were prepared in rabbits in our laboratory. The anti-IFN- $\gamma$ and anti-GMCSF monoclonal antibodies were purchased from R\&D (Minneapolis, Minnesota). Control IgG1 was derived from a control hybridoma (ATCC) and purified IgG1 and PE-conjugated CD3, CD8, CD16 and CD4 mAbs were purchased from Coulter/Immunotech (Miami, FL).

\section{Transfections and the generation of HEp2 cell transfectants}

The generation of HEp2 cell transfectants was described previously $[8,20]$. The stability of $\operatorname{I\kappa B}_{\left({ }_{(332 \mathrm{AS} 36 \mathrm{~A})}\right.}$ super repressor transfected HEp2 cells in blocking nuclear NFkB function in HEp2 cells were regularly checked by western blot analysis and EMSA using nuclear extracts prepared from the HEp2 cell transfectants.

\section{Purification of CD8+ T cells}

PBMCs from healthy donors were isolated as described before [21]. Briefly, peripheral blood lymphocytes were obtained after Ficollhypaque centrifugation and purified $\mathrm{CD}^{+} \mathrm{T}$ cells were negatively selected for by using a CD $8+\mathrm{T}$ cell isolation kit (Miltenyi Biotech) which contained greater than $90 \%$ CD8 + T cells by flow cytometric analysis of CD3+ CD8+ T cells (Figure 2). The levels of staining for CD16+ NK cells remained similar to the levels obtained after the staining with isotype control antibody staining, and were at $1.4 \% \pm 1 \%$ throughout the culturing procedures (Figure 2). In addition, purified NK cells were negatively selected by using an NK cell isolation kit (Stem Cell Technologies, Vancouver, Canada). The purity of NK cell population was found to be greater than $90 \%$ based on flow cytometric analysis of anti-CD16 antibody stained cells. The levels of contaminating CD3+ $\mathrm{T}$ cells remained low, at $2.4 \% \pm 1 \%$, similar to that obtained by the non-specific staining using isotype control antibody throughout the experimental procedures [15]. Written informed consents approved by UCLA Institutional Review Board (IRB) were obtained from the blood donors and all the procedures were approved by the UCLA-IRB.

\section{ELISA}

Wells of ELISA plates were coated with $50 \mu \mathrm{l}$ of monoclonal antibodies each specific for the IFN- $\gamma$ and GM-CSF. Plates coated with monoclonal antibodies were washed three to four times and blocked with ELISA /PBS containing 1\% BSA for 30 minutes before the addition of culture supernatants. Thereafter, the plates were washed twice and $50 \mu$ lof supernatants from treated $\mathrm{T}$ cell samples were added to each well. After overnight incubation at $37^{\circ} \mathrm{C}$, the plates were washed four times and $50 \mu \mathrm{l}$ of polyclonal antibody at 1:1000 dilutions specific for the cytokines measured was added to each well, and thereafter the incubation continued for an additional two hours at $37^{\circ} \mathrm{C}$. Alkaline phosphatase conjugated goat anti-rabbit IgG (Caltag) at a dilution of 1:2000 was added to each well and the plates were incubated for an additional $2 \mathrm{~h}$ at $37^{\circ} \mathrm{C}$. Finally, the plates were washed and incubated with the alkaline phosphatase substrate (Sigma 104) and read after $2 \mathrm{~h}$ in a titrated Multiskan MCC/240 ELISA reader using the $405 \mathrm{~nm}$ filter [7].

\section{${ }^{51} \mathrm{Cr}$ release assay}

The ${ }^{51} \mathrm{Cr}$ release assay was performed as described previously [7]. Briefly, different numbers of purified NK cells and CD8+ T cells were incubated with ${ }^{51} \mathrm{Cr}$-labeled tumor target cells. After a 4 hour incubation period the supernatants were harvested from each sample and counted for released radioactivity using the gamma counter. The percentage specific cytotoxicity was calculated as follows; \% Cytotoxicity = Experimental cpm - spontaneous cpm/Total cpm - spontaneous cpm $\mathrm{LU} 30 / 10^{6}$ is calculated by using the inverse of the number of effector cells required to lyse $30 \%$ of the tumor target cells X100.

${ }^{3} \mathrm{H}$ thymidine incorporation assay: After incubation of CD8+ T cells with the tumor cell transfectants for the number of days indicated in the result section, ${ }^{3} \mathrm{H}$ thymidine at $1 \mu \mathrm{Ci} /$ well was added to each well, and the incubation was continued for another 16-18 hours. The 
Citation: Jewett A, Nakamura H, Wang M, Teruel A, Paranjpe A, et al. (2012) Dedifferentiation of Epithelial Tumors Enhances Cytotoxicity, Survival and Expansion of Allogeneic CD8+ T Cells and Natural Killer Cells. J Carcinogen Mutagen S1:007. doi:10.4172/2157-2518.S1-007

Page 3 of 10

T cell samples were then harvested by a $\mathrm{PhD}$ harvester and the levels of incorporated ${ }^{3} \mathrm{H}$ thymidine were determined by counting the amount of radioactivity in the samples by a Liquid Scintillation Counter (LSC). Tumor cell transfectants were irradiated for one hour using $\gamma$ irradiator (Cs 137) before they were co-cultured with the cytotoxic effector cells.

\section{Multiplex cytokine protein arrays}

The fluorokine MAP cytokine multiplex array kits for measuring IFN- $\gamma$ and IL-6 were purchased from R\&D Systems and the procedures were conducted as suggested by the manufacturer. Briefly, the microparticle concentrates containing monoclonal antibodies against different cytokines were diluted with the microparticle diluent (provided in the kit). $50 \mu \mathrm{l}$ of each of microparticle concentrate was mixed with $5 \mathrm{~mL}$ of the diluent in a mixing bottle. $50 \mu \mathrm{l}$ of this mixture was then added to $50 \mu \mathrm{l}$ of the culture supernatants in each well of a microplate. The plate was incubated on a horizontal orbital microplate shaker at room temperature. After 3 hours of incubation the liquid was removed from the wells using a vacuum manifold. 100 $\mu \mathrm{l}$ of wash buffer was then added to each well and the wash step was repeated three times. $50 \mu$ of the secondary Biotin antibody cocktail specific for each analyte was then added to each well and the plate was incubated for an additional hour on a shaker at room temperature. The secondary antibody was prepared in the same way as the microparticle mixture/ primary antibody. This was followed by the wash step as described above. The PE conjugated Streptavidin provided in a $100 \mathrm{X}$ concentration was diluted to a $1 \mathrm{X}$ concentration with wash buffer just before use. $50 \mu \mathrm{l}$ of the Streptavidin-PE was then added to the wells for 30 minutes, after which the wash step was repeated. The microparticles were re-suspended in $100 \mu$ l of wash buffer after which they were incubated for an additional 2 minutes on a shaker and subsequently the plate was read using the Luminex 100 Analyzer. To analyze and obtain the cytokine concentrations a standard curve was generated by a three
A

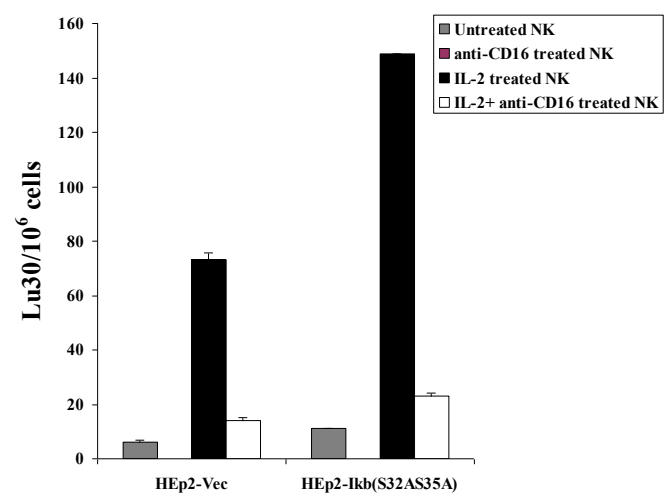

B

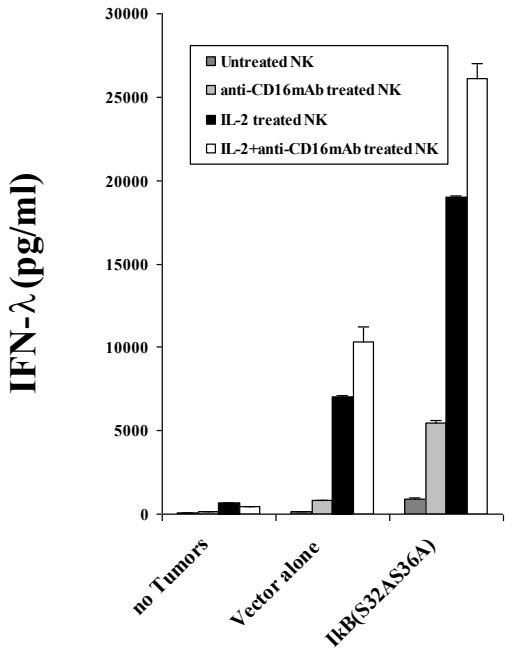

C

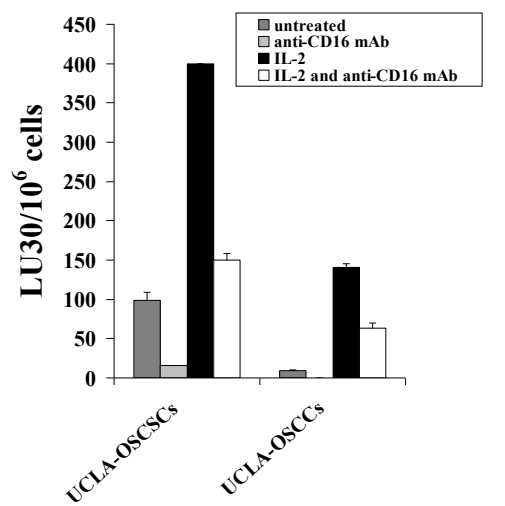

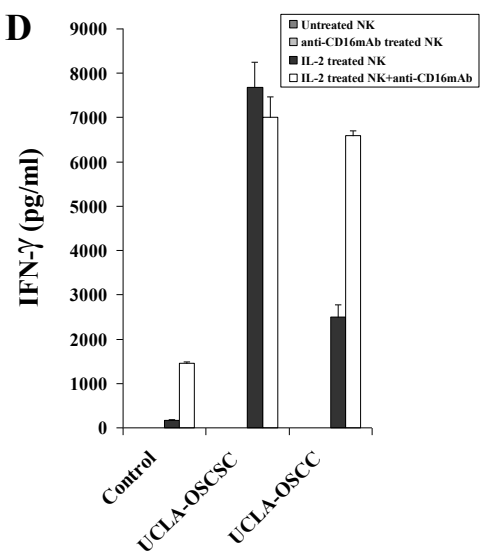
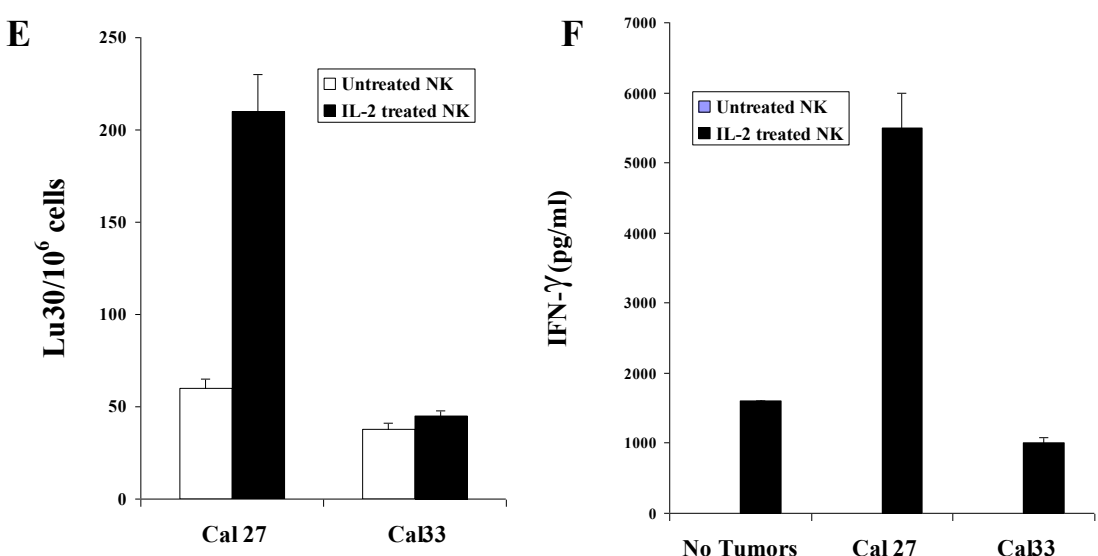

Figure 1: NFKB knock down HEp 2 cells as well as OSCSCs or Cal 27 tumors induce much higher induction of NK cell cytotoxicity and secretion of IFN-Y when compared to their more differentiated counterparts: NK cells $\left(1 \mathrm{X} 10^{6} / \mathrm{ml}\right)$ were left untreated or treated with IL-2 (1000 units/ml), or anti-CD $16 \mathrm{mAb}(3 \mu \mathrm{g} / \mathrm{ml})$ or a combination of IL-2 (1000 units/ml) and anti-CD16mAb $(3 \mu \mathrm{g} / \mathrm{ml})$ for $12-24$ hours before they were added to the following ${ }^{51} \mathrm{Cr}$ labeled tumors; vector alone transfected $\mathrm{HEp}-2$ cells (A), IKB ${ }_{(\mathrm{S} 32 \mathrm{AS} 36 \mathrm{~A})}$ transfected HEp2 cells (A), OSCSCs (C), OSCCs (C), Cal 27 (E) and Cal 33 (E) tumors. NK cell cytotoxicity were determined using a standard 4 hour ${ }^{51} \mathrm{Cr}$ release assay, and the lytic units $30 / 10^{6}$ were determined using inverse number of effectors required to lyse $30 \%$ of the tumor cells $X 100$. NK cells were also treated as described in Figure $1 \mathrm{~A}$ and they were either cultured in the absence of tumors or added to vector alone transfected $\mathrm{HEp}-2$ cells (B) and IkB ${ }_{(\mathrm{S} 32 \mathrm{As}}$ transfected HEp2 cells (B), OSCSCs (D), OSCCs (D), Cal 27 (F) and Cal 33 (F) at an effector to target ratio of 1:1. After an overnight culture, supernatants were removed from the cultures and the levels of IFN-y secretion were determined using specific ELISAs. One of five representative experiments is shown in this figure. 


\begin{tabular}{|c|c|}
\hline & IL-6 $(\mathbf{p g} / \mathrm{ml})$ \\
\hline HEp2-pRcCMV & $787 \pm 2$ \\
\hline HEp2-IKB ${ }_{(\text {S32AS36A) }}$ & $125 \pm 5$ \\
\hline OSCC & $2849 \pm 31$ \\
\hline OSCSCs & $0.0 \pm 1$ \\
\hline Cal-33 & $392 \pm 8$ \\
\hline Cal-27 & 0 \\
\hline
\end{tabular}

The tumor cells were cultured for 24-48 hours and the released IL-6 was measured using specific and sensitive ELISAs. The $p$ value for the difference between secretion of IL-6 in the vector alone transfected HEp2 cells and IKB transfected HEp2 cells as well as the difference between OSCCs and OSCSCs or Cal 27 and Cal 33 are less than 0.05. 1 of 5 representative experiments is shown in this table.

Table 1: NFKB knock down HEp2 cells as well as less differentiated OSCSCs or Cal 27 cells secrete no or very little IL-6.

fold dilution of recombinant cytokines provided by the manufacturer. The analysis was performed by the software provided by Luminex.

\section{Results}

Oral tumors which release no or low amounts of IL-6 are highly susceptible to NK cell mediated cytotoxicity

We have previously shown that blocking NFkB in HEp2 tumor cells or primary OSCCs or non-tumorigenic HOK-16B cells decreased IL-6 secretion substantially and resulted in an increased sensitivity of these cells to NK cell mediated cytotoxicity $[8,20]$. In this paper we expanded the number of different tumors which showed decreased secretion of IL- 6 (Table 1). Thus, using the levels of cytotoxicity, IFN- $\gamma$ and IL- 6 secretion, we could demonstrate a direct correlation between decreased IL- 6 and increased secretion of IFN- $\gamma$ and augmented NK cell cytotoxicity in the co-cultures of NK cells with the three tumor types, namely NFKB knock down HEp2 cells, OSCSC oral tumor stem like cells and $\mathrm{Cal} 27$ oral tumors (Table 1 and Figure 1). Both untreated and IL-2 treated NK cells lysed NFkB knock down HEp2, OSCSCs and $\mathrm{Cal} 27$ cells significantly more than vector-alone transfected HEp 2 cells,
OSCCs and Cal33 cells respectively (Figure 1). IL-2 treatment of NK cells resulted in a substantial increase in NK cell cytotoxicity (Figure 1). Treatment of NK cells with anti-CD16 antibody abrogated the ability of untreated and IL-2 treated NK cells to mediate cytotoxicity against vector-alone and NFkB knock down HEp2 cells and OSCCs and OSCSCs (Figure 1A and Figure 1C). Moreover, the addition of a combination of anti-CD16 antibody and IL-2 even though substantially lowered the ability of NK cells to lyse NFkB knock down HEp2 cells or OSCSCs when compared to IL-2 alone treated NK cells, the same treatment resulted in a significant induction of IFN $-\gamma$ secretion in the co-cultures of NK cells with the tumors (Figure 1B and Figure 1D). Therefore, increased IL- 6 secretion by the oral tumors may serve as a marker for decreased susceptibility of these tumors to NK cell mediated cytotoxicity and indicate the more differentiated phenotype of these tumors (Table 1).

NFkB knock down HEp2 tumor cells acquire increased susceptibility to $\mathrm{CD8}+\mathrm{T}$ cell cytotoxicity and trigger increased secretion of IFN- $\gamma$ and GMCSF by CD8+ T cells

To determine whether CD8+ T cells similar to NK cells were also induced to lyse NFKB knock down HEp2 cells, CD8+ T cells were purified from the peripheral blood (Figure 2) and treated with IL-2 and cultured with and without HEp2-IкB ${ }_{\left(\mathrm{S}_{22 \mathrm{AS} 36 \mathrm{~A})}\right.}$ cells for 18 days before they were washed, counted and added to either ${ }^{51} \mathrm{Cr}$ labeled HEp2-vec or ${ }^{51} \mathrm{Cr}$ labeled HEp2-IkB ${ }_{(\mathrm{S} 32 \mathrm{AS} 36 \mathrm{~A})}$ cells. IL-2 treated T cells

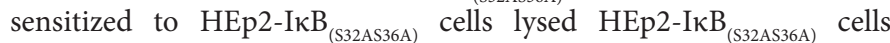
significantly more than HEp2-Vec (Figure 3A). IL-2 treated T cells in the absence of culturing with NFkB knock down HEp2 cells (data not shown) or with vector-alone transfected HEp-2 cells (please see below) demonstrated no or low lysis of HEp-2 cell transfectants. In addition, we cultured CD8+ T cells with vector-alone or NFkB knock down tumor cells and the levels of IFN- $\gamma$ and GM-CSF secretion were determined in the supernatants as a measure of CD8+ T cell activation. Supernatants recovered from the co-cultures of IL-2 treated CD8+ T cells and HEp2 $-\mathrm{IKB}_{(\mathrm{S} 32 \mathrm{AS} 36 \mathrm{~A})}$ tumor cells contained significantly higher levels of IFN- $\gamma$ (Figure 3B) and GM-CSF (Table 2) secretion when

\section{CD3}

Q: A

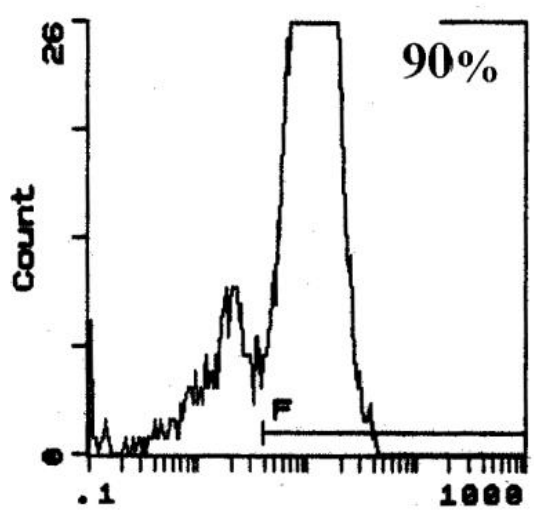

Q: A

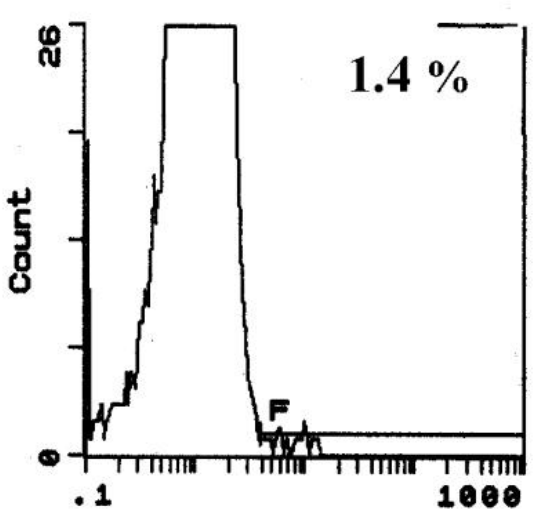

Q: A

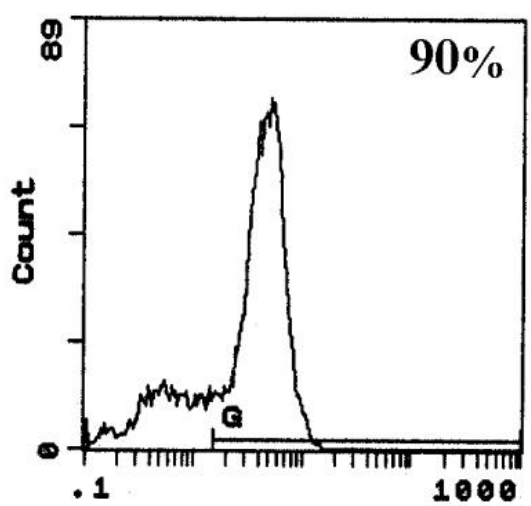

Figure 2: The purity of CD8+ T cells after isolation. The purity of CD8+ T cell populations were determined before and after co-culture with HEp2 tumor transfectants and the levels of CD3+ T cells, CD8+ T cells and CD3-CD16+ NK cells were determined using surface staining with specific antibodies. The percentages of CD8+ T cells, NK cells and CD3+ T cells were determined by flow cytometric analysis of antibody stained cells. One of several representative experiments is shown in this figure. 
Citation: Jewett A, Nakamura H, Wang M, Teruel A, Paranjpe A, et al. (2012) Dedifferentiation of Epithelial Tumors Enhances Cytotoxicity, Survival and Expansion of Allogeneic CD8+ T Cells and Natural Killer Cells. J Carcinogen Mutagen S1:007. doi:10.4172/2157-2518.S1-007

compared to those obtained from the co-cultures of IL-2 treated T cells with vector-alone HEp-2 cells. Increased induction of IFN- $\gamma$ and GM-CSF secretion could also be observed when HEp-2-IкB (S32AS36A) cells were co-incubated with untreated T cells as well as IL-2 treated $\mathrm{T}$ cells, albeit the levels of secreted cytokines were substantially higher in the presence of IL-2 treatment (Figure 3B and Table 2). Indeed, untreated $\mathrm{T}$ cells co-cultured with HEp2 -IкB ${ }_{(\mathrm{S} 32 \mathrm{AS} 36 \mathrm{~A})}$ tumor cells secreted higher or equal amounts of IFN- $\gamma$ when compared to IL-2 treated T cells co-cultured with vector-alone HEp2 cells (Figure 3B). Since IFN- $\gamma$ treatment has been shown to protect tumor cells from NK and CTL mediated cytotoxicity [22-24], we also determined whether blocking NFKB in tumor cells would abolish the protective effect of IFN- $\gamma$ on tumor cells. Thus, we treated vector-alone transfected HEp2 cells and HEp2 -IKB ${ }_{(S 32 A S 36 \mathrm{~A})}$ tumor cells with IFN- $\gamma$ prior to their coculture with $\mathrm{T}$ cells, and as expected, we found decreased amounts of IFN- $\gamma$ and GM-CSF secretion by IL- 2 treated CD $8+$ T cells cultured with IFN- $\gamma$ treated HEp2 cell transfectants (Figure 3B and Table 2). Increased cytokine secretion in CD8+ T cells with HEp2- I $B_{(\mathrm{S} 32 \mathrm{AS} 36 \mathrm{~A})}$ cell co-cultures could only be seen after 15 to 23 days of stimulation (Table 1) whereas significant secretion of cytokines by the NK cells in the co-cultures with HEp2-IKB ${ }_{(\mathrm{S} 32 \mathrm{AS} 36 \mathrm{~A})}$ cells could be seen as early as $18-24$ hours of incubation at $37^{\circ} \mathrm{C}[8,20]$. As indicated in the materials and methods section the levels of contaminating NK cells were checked regularly after the culture of CD8+ T cells with and without HEp2 cell transfectants, and they remained low at $1.4 \%$ throughout the experimental procedures (Figure 2).

NFkB knock down tumors enhanced IFN- $\gamma$ secretion in the presence of decreased IL-6 release in co-cultures with CD8+ T cells

When the levels of IL- 6 and IFN- $\gamma$ were considered on a multiplex cytokine array system we observed an inverse relationship between the secreted IL- 6 and those of IFN- $\gamma$, GM-CSF and TNF- $\alpha$ in the cocultures of PBMCs and NK cells with HEp2 cell transfectants $[8,24]$. Thus, we wanted to know whether supernatants obtained from CD8+ $\mathrm{T}$ cells cultured with HEp2 cell transfectants also contained inverse secretion of IFN- $\gamma$ and IL-6. As demonstrated in Figure 3C the levels of IL-6 secretion in the supernatants were higher in the co-cultures of CD8+ $\mathrm{T}$ cells with vector-alone transfected HEp2 cells when compared to those obtained from co-cultures of CD8+ T cells with HEp2-IKB ${ }_{(\mathrm{S} 32 \mathrm{AS} 36 \mathrm{~A})}$ cells (Figure 3C). In contrast, the levels of secreted IFN- $\gamma$ were significantly higher in the co-cultures of CD8+ T cells and $\mathrm{I} \kappa \mathrm{B}_{(\mathrm{S} 32 \mathrm{AS} 36 \mathrm{~A})}$ transfected HEp2 cells when compared to those obtained from the co-cultures of $\mathrm{CD} 8+\mathrm{T}$ cells with vector-alone transfected HEp2 cells (Figure 3C). When considering the ratios of IL-6 to IFN- $\gamma$, lower ratios of IL- 6 to IFN- $\gamma$ secretion was obtained when CD8+ T cells were activated by HEp2- IאB ${ }_{(S 32 \mathrm{AS} 36 \mathrm{~A})}$ cells as compared to vectoralone transfected HEp2 cells (Figure 3D). Indeed, there was a direct corelation between increased cytotoxicity and cell survival and decreased ratios of IL-6 to IFN- $\gamma$ in co-cultures of CD8+ T cells with HEp2 cell transfectants (Figure 3-5). Therefore, the ratios of IL-6 to IFN- $\gamma$ may be a better indicator of CD8+ T cell survival and function than each cytokine alone after interaction with oral tumors. In addition, either $\mathrm{T}$ cells alone or tumor cell transfectants alone were unable to secrete significant amounts of IFN- $\gamma$ or IL-6, whereas the addition of T cells to tumor cells synergistically increased the levels of secreted cytokines (Figure 3C).

\section{Survival and expansion of CD8+ T cells is dependent on HEp2 tumor cell NFKB activity}

Untreated or IL-2 treated CD8+ T cells were co-cultured with or without vector-alone or $\mathrm{I}_{\mathrm{B}} \mathrm{B}_{(\mathrm{S} 32 \mathrm{AS} 36 \mathrm{~A})}$ transfected HEp2 cells and the levels of $\mathrm{CD}^{+} \mathrm{T}$ cell survival were assessed by microscopy using trypan blue exclusion assay, and the rate of $\mathrm{T}$ cell proliferation by measuring the levels of ${ }^{3} \mathrm{H}$ thymidine incorporation. Addition of vector-alone transfected HEp2 cells to IL-2 treated $\mathrm{CD}^{+} \mathrm{T}$ cells resulted in a significant decrease in $\mathrm{T}$ cell numbers compared to either $\mathrm{T}$ cells in the absence of tumor cells or T cells co-cultured with HEp2-IkB ${ }_{(532 \mathrm{AS} 36 \mathrm{~A})}$ cells (Figure 4). As expected, untreated $\mathrm{T}$ cells when co-cultured with or without HEp2 cell transfectants exhibited significant decreases in the numbers of cells when compared to the $1 \mathrm{X} 10^{6}$ cells $/ \mathrm{ml}$ input numbers of $\mathrm{T}$ cells at the initiation of the cultures (Figure 4). In addition, when compared to the input number of $1 \mathrm{X} 10^{6}$ cells $/ \mathrm{ml}$ of IL- 2 treated T cells at the initiation of the cultures significant decreases in the numbers of IL-2 treated T cells could be seen at days 15 (data not shown) and 24 of cultures when IL-2 treated T cells were cultured with vector-alone transfected HEp2 cells (Figure 4). In contrast, when compared to $1 \mathrm{X} 10^{6}$ cells/ml input IL-2 treated T cells at the initiation of the cultures, the numbers of IL-2 treated T cells rose substantially, exceeding those which were cultured in the absence of any tumors or in the presence of vector-alone transfected HEp2 cells, when IL-2 treated T cells were co-cultured with $\operatorname{I\kappa B}_{(\mathrm{S} 32 \mathrm{AS} 36 \mathrm{~A})}$ transfected HEp2 cells (Figure 4). Pretreatment of tumor cells with IFN- $\gamma$ decreased the numbers of IL-2 treated CD8 $+\mathrm{T}$ cells in both vector alone and $\mathrm{IKB}_{(\mathrm{S} 32 \mathrm{AS} 36 \mathrm{~A})}$ transfected HEp2 cells (Figure 4). However, the decrease was more profound when the T cells were cultured with vector-alone transfected HEp2 cells (62\% decrease) than with $\mathrm{I}_{\mathrm{K}} \mathrm{BS}_{(\mathrm{S} 2 \mathrm{AS} 36 \mathrm{~A})}$ transfected HEp2 cells (30\% decrease), an approximately $50 \%$ decline in the loss of $\mathrm{T}$ cells when cultured with IFN- $\gamma$ treated HEp2 $-\mathrm{I} \mathrm{B}_{(\mathrm{S} 32 \mathrm{AS} 36 \mathrm{AA})}$ cells when compared to IFN- $\gamma$ treated HEp2-Vec cells (Figure 4).

In addition to determining the numbers of $\mathrm{T}$ cells we measured the rate of proliferation in IL-2 treated T cells cultured with HEp2 cell transfectants using ${ }^{3} \mathrm{H}$ thymidine incorporation assay. The levels of ${ }^{3} \mathrm{H}$ thymidine incorporation were lower in co-cultures of IL-2 treated T cells with vector-alone transfected HEp2 cells as compared to T cell cultures which either did not receive any tumor cells (range of $41 \%$ to $50 \%$ decrease) or were co-cultured with HEp2-IaB ${ }_{(\mathrm{S} 32 \mathrm{AS} 36 \mathrm{~A})}$ cells (range of $68 \%$ to $81 \%$ decrease) (Table 3). As expected, significant differences in the thymidine incorporation between samples could only be seen in IL-2 treated T cells and not in untreated T cell cultures (Table 3). Loss of $\mathrm{T}$ cell proliferation in the co-cultures of $\mathrm{T}$ cells with vectoralone transfected HEp2 cells was more dramatic when HEp2 cells were pre-treated with IFN- $\gamma$ (range of $56 \%$ to $63 \%$ decrease) (Table 3). IL-2 treated $\mathrm{T}$ cell proliferation remained significantly higher in co-cultures of $\mathrm{T}$ cells with untreated and IFN- $\gamma$ treated HEp2-IкB ${ }_{(\mathrm{S} 32 \mathrm{AS} 36 \mathrm{~A})}$ cells compared to either $\mathrm{T}$ cells in the absence of tumors or those which were cultured with untreated and IFN- $\gamma$ treated vector-alone transfected HEp2 cells (Table 3).

The decrease in the rate of proliferation of CD8+ T cells between those co-cultured with untreated and IFN- $\gamma$ treated HEp2 tumor cell transfectants was on average lower in the co-cultures with NFkB knock down HEp2 cells when compared to vector-alone transfected HEp2 cells. In co-cultures of vector-alone HEp2 cells with CD8+ T cells pre- 
A

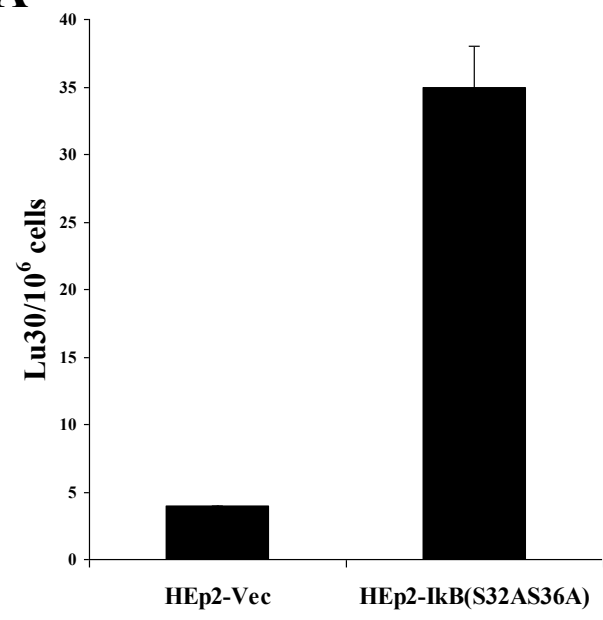

C

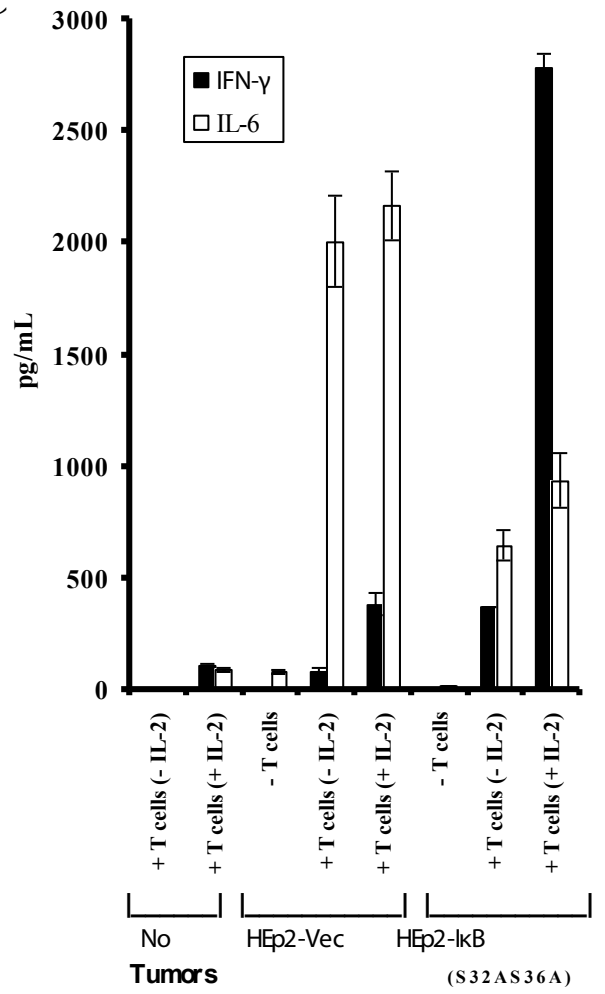

B

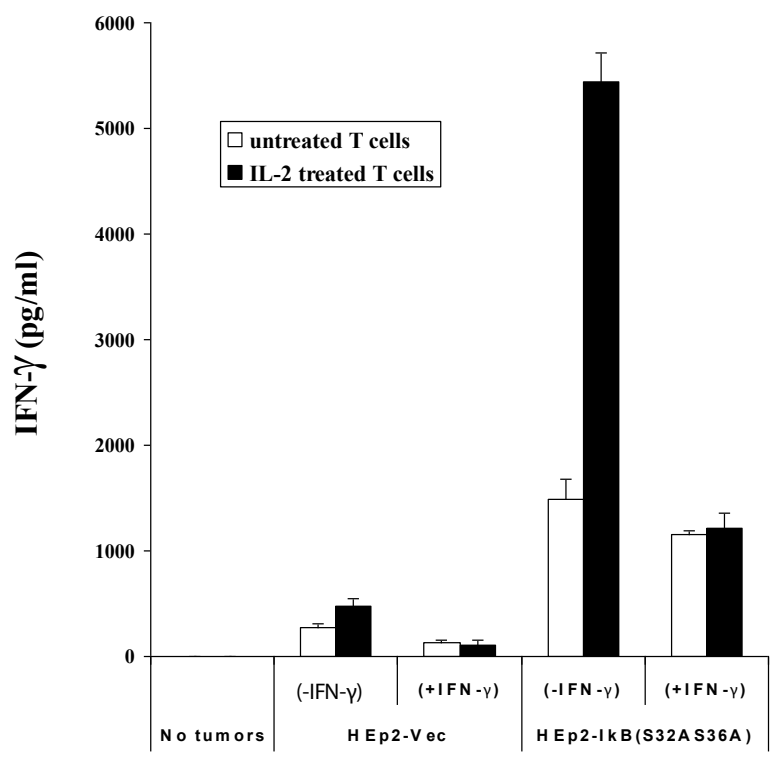

D

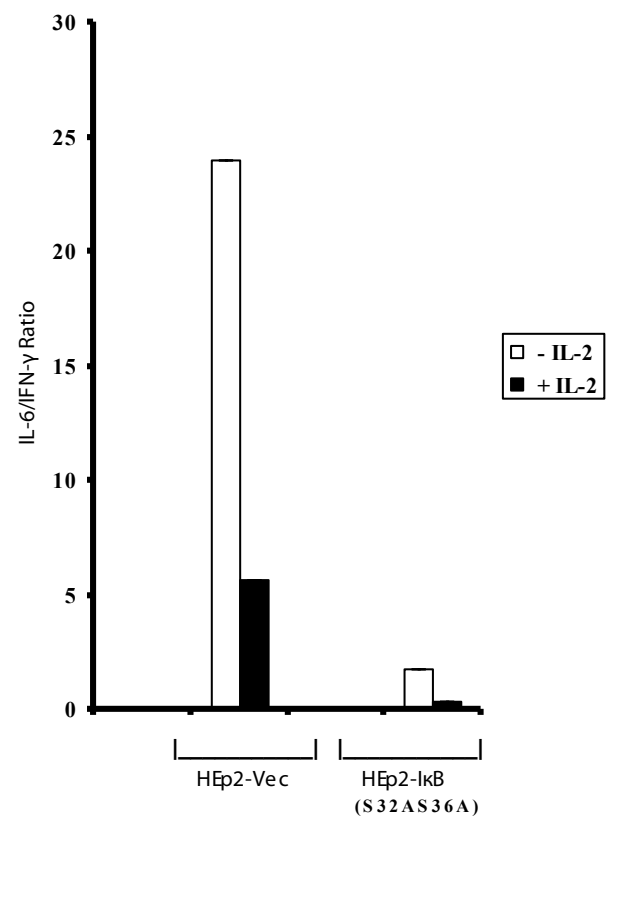

Figure 3: NFKB knock down HEp2 tumor cells acquire increased susceptibility to CD8+ T cell cytotoxicity, and trigger increased secretion of IFN- $y$ in the presence of decreased IL-6 secretion. (A) T cells were treated with IL-2 (500 units/mI) and cultured with and without HEp2-IKB ${ }_{(S 32 A S 36 \mathrm{~A})}$ cells for 18 days before they were washed, counted and added to either ${ }^{51} \mathrm{Cr}$ labeled $\mathrm{HEp} 2$-vec or ${ }^{51} \mathrm{Cr}$ labeled $\mathrm{HEp} 2-\mathrm{IKB}{ }_{\left({ }_{332 A S 36 \mathrm{~A}}\right)}$ cells. T cell cytotoxicity were determined using a standard $4 \mathrm{hour}{ }^{51} \mathrm{Cr}$ release assay, and the lytic units 30/106 were determined using inverse number of effectors required to lyse 30\% of the tumor cells X 100. (B) Purified CD8+ T cells were treated with and without IL-2 $(500 \mu / \mathrm{ml})$ overnight before their co-culture with and without IFN-Y $(200 \mathrm{u} / \mathrm{ml})$ pre-treated vector alone and IKB ${ }_{(S 32 A S 36 A)}$ transfected HEp2 cells $\left(E: T\right.$ ratio 1:1). After two weekly stimulations with freshly supplemented IL2, the supernatants were removed from the CD8+ T/HEp2 cell cO-cultures at day $18^{\text {th }}$ and assayed for released IFN- by specific and sensitive ELISA assay. IFN-y treated HEp2 cell transfectants were washed three times before they were added to CD8+ $T$ cells. The $\mathrm{p}$ value for the difference between secretion of IFN- in the co-cultures of CD8+ T cells with vector-alone transfected HEp2 cells vs. IKB $\mathrm{HEp} 2$ cells were less than 0.05 . (C) CD8+ T cells were treated with and without IL-2 $(500 \mathrm{u} / \mathrm{ml})$ before their co-culture with vector-alone and IKB (S32AS36A) $_{\text {(Sansansfected HEp2 }}$ cells $\left(E: T\right.$ ratio 1:1). After two weekly stimulations with freshly supplemented IL2, the supernatants were removed from the CD8+ $T / H E p 2$ cell $C O-c 3$-cultures at day $18^{\text {th }}$ and assayed for the released IL-6 and IFN- $y$ using antibody coated multiplex microbead immunoassay kit obtained from R\&D. The $p$ values for the differences in secretion of IL-6 and IFN-y between the T cells co-cultured with vector-alone vs. IKB transfected HEp2 cells were at less than 0.05. (D) The ratio for secreted levels of IL-6 to IFN-y was calculated for T cells co-cultured with each of HEp2 cell transfectants. 1 of 4 representative experiments is shown in this figure. 
Citation: Jewett A, Nakamura H, Wang M, Teruel A, Paranjpe A, et al. (2012) Dedifferentiation of Epithelial Tumors Enhances Cytotoxicity, Survival and Expansion of Allogeneic CD8+ T Cells and Natural Killer Cells. J Carcinogen Mutagen S1:007. doi:10.4172/2157-2518.S1-007

\begin{tabular}{|c|c|c|c|c|c|c|}
\hline \multirow[b]{2}{*}{ day } & \multirow[b]{2}{*}{ T cells $-/+\mathrm{IL}_{2}$} & \multirow[t]{2}{*}{$\begin{array}{c}\text { T cells (No tumors) } \\
(\mathrm{pg} / \mathrm{ml})\end{array}$} & \multicolumn{2}{|c|}{ T+HEp2-vec (pg/ml) } & \multicolumn{2}{|c|}{$T+H E p 2-I K B_{(S 32 A S 36 A)}(p g / m l)$} \\
\hline & & & - IFN-Y & + IFN-Y & - IFN-Y & + IFN-Y \\
\hline \multirow[t]{2}{*}{15} & - & $0.0 \pm 0.0$ & $1.5 \pm 0.7$ & $5 \pm 2.8$ & $11 \pm 0.0$ & $7.5 \pm 4.9$ \\
\hline & + & $4 \pm 0.0$ & $16.5 \pm 0.7$ & $8 \pm 1.4$ & $185 \pm 10$ & $104.5 \pm 18$ \\
\hline \multirow[t]{2}{*}{19} & - & $9 \pm 0.0$ & $6 \pm 4.2$ & $3.5 \pm 2.1$ & $16 \pm 0.0$ & $5 \pm 0.0$ \\
\hline & + & $51.5 \pm 25$ & $14.5 \pm 9.2$ & $10 \pm 0.0$ & $341.5 \pm 20$ & $231 \pm 42$ \\
\hline \multirow[t]{2}{*}{23} & - & $0.0 \pm 0.0$ & $0.0 \pm 0.0$ & $0.0 \pm 0.0$ & $23 \pm 0.0$ & $7.5 \pm 0.7$ \\
\hline & + & $9.5 \pm 0.7$ & $13.5 \pm 4.9$ & $26.5 \pm 2.1$ & $1243 \pm 25$ & $465.5 \pm 16$ \\
\hline
\end{tabular}

Purified CD8+ T cells were treated with and without IL-2 (500 u/ml) overnight before their co-culture with and without IFN- $(200 \mathrm{u} / \mathrm{ml})$ treated vector alone and IKB ${ }_{(\mathrm{S} 32 \mathrm{AS} 36 \mathrm{~A})}$ transfected HEp2 cells (E:T ratio 1:1). After two weekly stimulations with freshly supplemented IL2, the supernatants were removed from the CD8+ $T$ /HEp2 cell cocultures at the indicated days in the table and assayed for released GM-CSF by a specific and sensitive ELISA. IFN- $y$ treated HEp2 cell transfectants were washed three

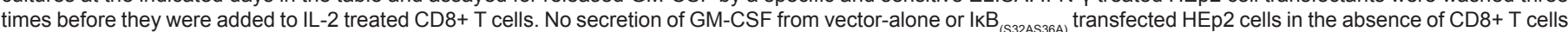
could be observed (data not shown). The $p$ value for the difference between secretion of GM-CSF in the co-cultures of CD8+ T cells with control HEp2-vec and IKB ${ }_{(S 32 A S 36 A)}$ transfected HEp2 cells are less than 0.05 . 1 of 3 representative experiments is shown in this table.

Table 2: Kinetics of increased GM-CSF release when CD8+ T cells were co-cultured with untreated and IFN-y treated HEp2-IKB ${ }_{(\mathrm{S} 32 \mathrm{AS} 36 \mathrm{~A})}$ cells

\begin{tabular}{|c|c|c|c|c|c|c|}
\hline & \multirow[b]{2}{*}{$\mathrm{T}$ cells $-/+\mathrm{IL}_{2}$} & \multirow[t]{2}{*}{$\begin{array}{l}\text { T cells (no tumors) } \\
\text { (cpm) }\end{array}$} & \multicolumn{2}{|c|}{ T+ HEp2-vec (cpm) } & \multicolumn{2}{|c|}{$\mathrm{T}+\mathrm{HEp} 2-\mathrm{I}_{\mathrm{K}} \mathrm{B}_{(\mathrm{S} 32 \mathrm{AS} 36 \mathrm{~A})}(\mathrm{cpm})$} \\
\hline & & & - IFN-Y & + IFN-Y & - IFN-Y & + IFN-Y \\
\hline \multirow[t]{2}{*}{ Exp\#1 } & - & $4259 \pm 402$ & $4514 \pm 1066$ & $3889 \pm 1268$ & $8729 \pm 558$ & $5562 \pm 398$ \\
\hline & + & $17866 \pm 205$ & $8937 \pm 394$ & $6866 \pm 564$ & $47189 \pm 1327$ & ND \\
\hline \multicolumn{7}{|l|}{ Exp \#2 } \\
\hline & - & $1976 \pm 100$ & $3516 \pm 535$ & $3588 \pm 1088$ & $3676 \pm 524$ & $3038 \pm 365$ \\
\hline & + & $14273 \pm 1435$ & $8364 \pm 1049$ & $6216 \pm 495$ & $25940 \pm 1504$ & $19605 \pm 1295$ \\
\hline \multicolumn{7}{|l|}{ Exp \#3 } \\
\hline & - & $1760 \pm 390$ & $4635 \pm 2726$ & $4995 \pm 1381$ & $5267 \pm 1385$ & $6153 \pm 2767$ \\
\hline & + & $18184 \pm 1128$ & $10311 \pm 1603$ & $6784 \pm 1769$ & $32174 \pm 2513$ & $27374 \pm 3589$ \\
\hline
\end{tabular}

Purified CD8+ T cells $\left(1 \times 10^{6}\right.$ cells per sample) were treated with IL-2 (500u/ml) before their co-culture with untreated and IFN- $y$ pre-treated (200u/ml), irradiated vectoralone and IKB transfected HEp2 cells (E:T ratio of 1:1). After 18 days of incubation $100 \mu$ lof each sample were removed and added in triplicates to 96 well flat bottom plates and the incubation continued in the presence of $1 \mu \mathrm{Ci} /$ well of ${ }^{3} \mathrm{H}$ thymidine for another $16-18$ hours. IFN- $\gamma$ pre-treated $\mathrm{HEp} 2$ cell transfectants were washed three times before they were added to CD8+ T cells. The p value for the differences between the co-cultures of IL-2 treated CD8+ T cells with control HEp2 cells vs. $\mathrm{IKB}_{(\mathrm{S} 32 \mathrm{AS} 36 \mathrm{~A})}$ transfected HEp2 cells were less than 0.05. ND (not done)

Table 3: Inhibition of CD8+ T cell thymidine incorporation after interaction of CD8+ T cells with vector-alone transfected HEp2 cells but not with HEp2-IKB ${ }_{(\mathrm{S} 32 \mathrm{AS} 36 \mathrm{~A})}$ cells.

treatment of tumor cells with IFN- $\gamma$ resulted in $23 \%$ to $34 \%$ loss of $\mathrm{T}$ cell proliferation when compared to the co-cultures with untreated tumor cells. In contrast, in co-cultures containing HEp2-IкB ${ }_{(\mathrm{S} 32 \mathrm{AS} 36 \mathrm{~A})}$ cells with CD8+ T cells IFN- $\gamma$ pre-treatment of tumor cells reduced T cell proliferation only by $15 \%-24 \%$ when compared to the co-cultures with untreated HEp2 -IKB ${ }_{(\mathrm{S} 32 \mathrm{AS} 36 \mathrm{~A})}$ cells (Table 3). Therefore, both cell loss and decreased proliferation could be observed when CD8+ T cells were co-cultured with vector-alone transfected HEp2 cells whereas $\mathrm{T}$ cell expansion could be observed when cultured with NFkB knock down HEp-2 cells.

\section{Allogeneic CD8+ T cells when sensitized by IFN- $\gamma$ treated HEp-2 cell transfectants have lower ability to lyse HEp 2 tumors}

T cells were treated with IL-2 and cultured with either untreated or IFN- $\gamma$ treated irradiated HEp2-Vec or HEp2-IкB ${ }_{(\mathrm{S} 32 \mathrm{AS} 36 \mathrm{~A})}$ cells for 18 days before they were washed, counted and added to either ${ }^{51} \mathrm{Cr}$ labeled HEp2-vec or ${ }^{51} \mathrm{Cr}$ labeled HEp2-IкB ${ }_{(\mathrm{S} 32 \mathrm{AS} 36 \mathrm{~A})}$ cells. No contaminating tumor cells could be seen by microscopic examination in the cocultures of CD8+ T cells and HEp2 tumor cell transfectants at the day $18^{\text {th }}$ of co-cultures (data not shown). IL-2 treated T cells sensitized with vector-alone transfected HEp2 cells displayed reduced lysis of ${ }^{51} \mathrm{Cr}$ labeled HEp2-Vec or HEp2-IкB ${ }_{(\mathrm{S} 32 \mathrm{AS} 36 \mathrm{~A})}$ cells (Figure 5). In contrast, T cells sensitized with HEp2-IкB ${ }_{(\mathrm{S} 32 \mathrm{AS} 36 \mathrm{~A})}$ cells lysed ${ }^{51} \mathrm{Cr}$ labeled HEp2vec or HEp2-IKB ${ }_{(\text {(32AS36A) }}$ cells significantly more than $\mathrm{T}$ cells cocultured with vector-alone transfected HEp2 cells (Figure 5). However, in both cases higher lysis of NFkB knock down tumors were seen by $\mathrm{T}$ cells when compared to vector-alone transfected HEp2 cells. IL2 treated T cells co-cultured with IFN- $\gamma$ treated tumor transfectants had reduced ability to lyse ${ }^{51} \mathrm{Cr}$ labeled HEp2 tumor cell transfectants when compared to those cultured with untreated tumor cells. Collectively these data suggest that blocking NFKB function in tumor cells makes them susceptible to allogeneic CD8+ T cell mediated cytotoxicity.

\section{Discussion}

We have previously shown that inhibition of NFkB in HEp2 tumor cells results in activation of $\mathrm{NK}$ cell cytotoxic function and in an increase in the levels of IFN- $\gamma$ secretion by the NK cells $[8,24]$. In this paper we demonstrate that allogeneic CD8+ T cell cytotoxic function is also increased against NFkB knock down tumor cells. Moreover, two oral tumors OSCSCs and Cal 27 exhibiting decreased secretion of IL-6 similar to NFkB knock down HEp2 cells are highly susceptible 
Citation: Jewett A, Nakamura H, Wang M, Teruel A, Paranjpe A, et al. (2012) Dedifferentiation of Epithelial Tumors Enhances Cytotoxicity, Survival and Expansion of Allogeneic CD8+ T Cells and Natural Killer Cells. J Carcinogen Mutagen S1:007. doi:10.4172/2157-2518.S1-007

Page 8 of 10

to NK cell mediated cytotoxicity, whereas their corresponding more differentiated cells which secrete higher levels of IL-6 are resistant to NK cell mediated cytotoxicity.

NFאB knock down HEp2 cells grew at a relatively faster rate than vector-alone transfected HEp2 cells and became highly resistant to NK cell mediated cytotoxicity when treated with a combination of IFN- $\gamma$ and TNF- $\gamma$. In addition, the size of the cells remained smaller than the vector-alone transfected HEp2 cells.

The increased lysis of HEp-2-IkB ${ }_{(\mathrm{S} 32 \mathrm{AS} 36 \mathrm{~A})}$ cells by T cells was not due to an increased sensitivity of these cells to $\mathrm{T}$ cell elaborated apoptotic factors since, supernatants obtained from the co-cultures of $\mathrm{T}$ cells and

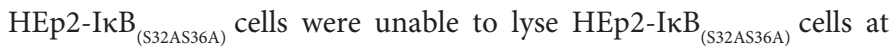
4-6 hour time points, unlike direct CD8+ T cell lysis (data not shown). Therefore, direct contact between the T cells and HEp2-IкB (S32AS36A) cells was necessary for the lysis of tumor cells.

Numbers of $\mathrm{T}$ cells co-cultured in the presence of IKB transfected HEp2 cells increased over time when compared to the input numbers at the initiation of the $\mathrm{T}$ cell and tumor cell cocultures. In contrast, $\mathrm{T}$ cell numbers decreased substantially over time after interaction with vector-alone transfected HEp2 cells. Therefore, blocking NFkB function in HEp2 cells was found to decrease the ability of HEp2 cells to induce depletion of T cells. This observation is of significance since it does imply that when cells are differentiated they

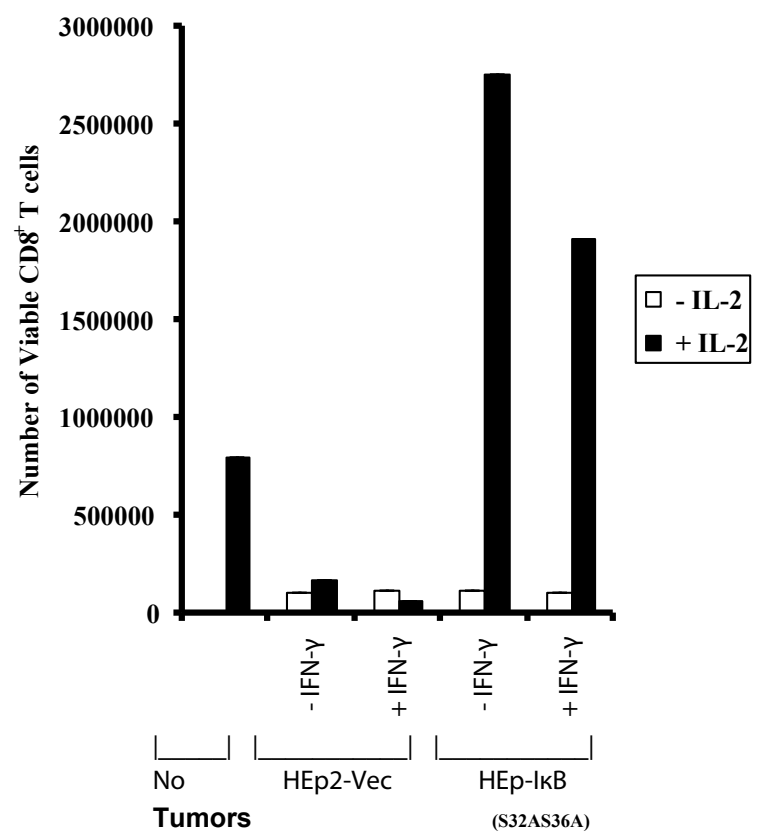

Figure 4: Expansion of CD8+ T cell numbers after interaction with HEp2$\mathrm{IkB}_{\left(\mathrm{S}_{32 \mathrm{AS} 36 \mathrm{~A}} \text { cells is in contrast with contraction of } \mathrm{CD} 8+\mathrm{T} \text { cells after }\right.}$ interaction with vector-alone transfected HEp2 cells: (A) Purified CD8+ T cells $\left(1 \times 10^{6}\right.$ cells per sample) were treated with and without IL-2 $(500 \mathrm{u} / \mathrm{ml})$ overnight before their co-culture with untreated and IFN- $\gamma$ pre-treated (200u/ $\mathrm{ml}$ ), irradiated vector-alone and $\mathrm{IKB}_{(\mathrm{S} 32 \mathrm{AS} 36 \mathrm{~A})}$ transfected $\mathrm{HEp} 2$ cells (E:T ratio of $1: 1)$. After two weekly stimulations with freshly supplemented IL2, the cells were removed from the CD8+ T/HEp2 cell co-cultures at day $18^{\text {th }}$ and the numbers of effector cells were determined in each sample by microscopic counting of viable $T$ cells by Trypan blue exclusion assay. The numbers of effector cells were determined by three independent observers. One of four representative experiments is shown in this figure. One of four representative experiments is shown in this figure. result in the deletion of NK and T cells. Similar effects of HEp2 cell transfectants on NK cell survival were also observed previously [8].

Inhibition of NFkB in HEp2 cells increased secretion of IFN- $\gamma$ and GM-CSF by CD8+ T cells whereas secretion of IL- 6 was significantly inhibited. In contrast, CD8+ T cells and vector-alone transfected HEp2 cells each secreted moderate to low levels of IL- 6 and IFN- $\gamma$, and coincubation of these cells together increased substantially the secreted levels of IL- 6 while triggering lower levels of IFN- $\gamma$ secretion. IL-6 secretion by HEp2- I $\kappa B_{\left(\mathrm{S}_{32 \mathrm{AS} 36 \mathrm{~A})}\right.}$ cells was lower than in vector alone transfected HEp2 cells. IL- 6 is secreted constitutively by a number of oral Squamous cell carcinomas [25]. IL-6 is known to interfere with IFN- $\gamma$ signaling by the induction of Th2 differentiation [26]. Furthermore, induction of Stat 3 activation is observed after IL-6 treatment [26]. Since blocking of Stat3 function in tumor cells is shown to inhibit tumor mediated inactivation of adaptive immunity [27], it is likely that IL-6 induced Stat3 function in the co-cultures of $\mathrm{T}$ cells and vector-alone transfected HEp2 cells is in part responsible for the induction of CD8+ T cell inactivation. This possibility is under investigation in our laboratory presently.

It is clear that the kinetics and timing of activation is quite different between NK cells and CD8+ T cells when cultured with HEp2 tumor cell transfectants. Whereas NK cells can be activated within 24 hours to secrete substantial amounts of IFN- $\gamma$, and lyse their respective tumors in 4 hours, CD8+ T cells required a minimum of two to three weeks to demonstrate increased secretion of IFN- $\gamma$ and the lysis of tumor cells. Indeed, when tested in parallel, we observed no cytotoxicity or secretion of IFN- $\gamma$ by the co-cultures of tumor transfectants with CD8+ T cells within the time period when significant lysis of tumors and secretion of IFN- $\gamma$ could be observed by the co-cultures of NK cells with HEp2 tumor transfectants (data not shown).

IFN- $\gamma$ is known to protect the cells from NK or T cell mediated lysis resulting in the loss of NK or T cell function and cell numbers [2224]. Similarly, we show here that IFN- $\gamma$ treatment causes suppression of CTL mediated cytotoxicity against both NFkB knock down cells and vector-alone transfected HEp-2 cells. Such effect is likely due to induction of differentiation and loss of susceptibility to NK or CTL mediated lysis. We also observed a significant decline in the number and the activity of CD8+ T cells when they were co-cultured with IFN- $\gamma$ pre-treated control HEp2 cells (Figure 3-5). Indeed, IFN- $\gamma$ is known to not only augment the expression of MHC-Class I $[1,22,23,28]$, but also it increases a number of important inhibitory ligands such as $\mathrm{B} 7 \mathrm{H} 1$. Interestingly, IFN- $\gamma$ treatment augmented the expression of $\mathrm{B} 7 \mathrm{H} 1$ inhibitory ligand on HEp2-vec cells to a greater extent than in HEp2I $\kappa B_{(\mathrm{S} 32 \mathrm{AS} 36 \mathrm{~A})}$ cells after IFN- $\gamma$ treatment (data not shown) correlating with the lower ability of IFN- $\gamma$ treated HEp2-IkB ${ }_{(\mathrm{S} 32 \mathrm{AS} 36 \mathrm{~A})}$ cells to induce inactivation of cytotoxic function of IL-2 treated CD8+ T cells (Figure 5). Whether inability to upregulate inhibitory surface receptors in HEp2-IKB ${ }_{(\mathrm{S} 32 \mathrm{AS} 36 \mathrm{~A})}$ cells is responsible for $\mathrm{NK}$ and $\mathrm{CD} 8+\mathrm{T}$ cells mediated cytotoxicity should await future investigation.

Even though the magnitude of IFN- $\gamma$ protective effects, especially in terms of CTL numbers and proliferation, in co-cultures of T cells with IFN- $\gamma$ treated IкB ${ }_{(\text {S32AS36A) }}$ transfected HEp2 cells was somewhat less than that seen in the co-cultures of T cells with IFN- $\gamma$ treated vector-alone transfected HEp2 cells, we could still observe significant functional differences between IFN- $\gamma$ treated and untreated HEp2-IкB 


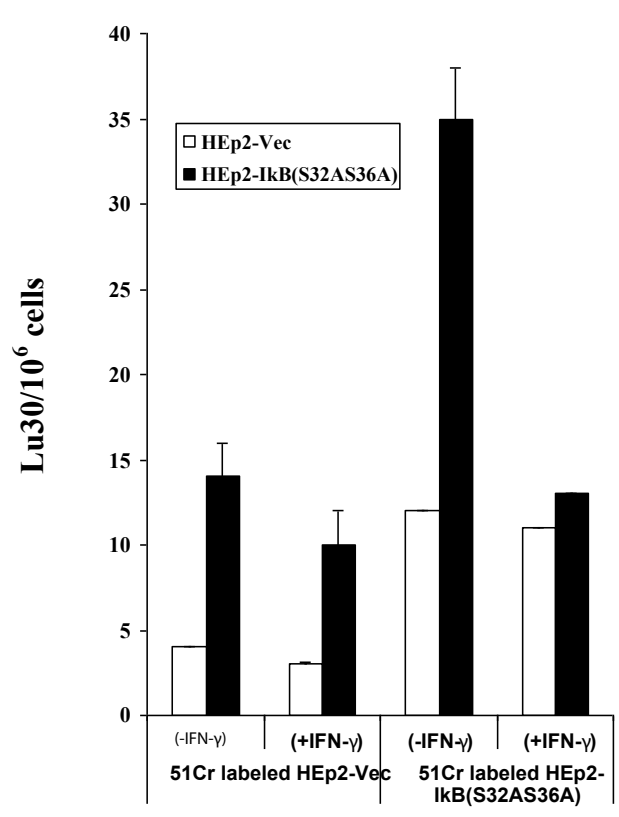

Figure 5: Increased lysis of IKB inhibition of HEp2 tumor cell cytotoxicity after exposure of T cells to HEp2vec but not HEp2-IKB (S32AS36A) cells: CD8+ T cells were treated with IL2 (500 $\mathrm{u} / \mathrm{ml}$ ) and cultured with each of untreated or IFN-y treated vector-alone and

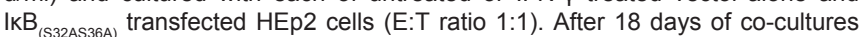
the samples were washed twice, the number of surviving CD8+ T cells counted and adjusted to $1 \times 10^{6} / \mathrm{ml}$ before they were added to ${ }^{51} \mathrm{Cr}$ labeled $\mathrm{HEp} 2$-vec and HEp2- IKB cells. After 4-6 hours of incubation at $37^{\circ} \mathrm{C}$, supernatants were harvested and the levels of released ${ }^{51} \mathrm{Cr}$ radioactivity were determined by a $Y$ counter. LU $30 / 10^{6}$ is calculated by using the inverse of the number of effector cells needed to lyse $30 \%$ of tumor target cells X100. The p values for the difference between the co-cultures of $T$ cells with vector-alone transfected $\mathrm{HEp} 2$ cells and with $\mathrm{IKB}_{(\mathrm{S} 32 \mathrm{AS} 36 \mathrm{~A})}$ transfected $\mathrm{HEp} 2$ cells are less than 0.05 . One of 6 representative experiments is shown in this Figure.

cells on $\mathrm{T}$ cell function. This indicated that there is an NFKB independent effect of IFN- $\gamma$ on protection of HEp2 cells since no NFKB could be induced in HEp2-IкB ${ }_{(\mathrm{S} 32 \mathrm{AS} 36 \mathrm{~A})}$ cells even when a very sensitive system of $\mathrm{NF \kappa B}$ measurement was employed to assess the levels of $\mathrm{NF \kappa B}$ function [29]. Therefore, IFN- $\gamma$ may function through NFkB dependent and independent pathways to protect the tumors from NK and CTL functions.

Overall, it appears that the magnitude of NFkB expressed in tumors are important for providing signals which either limit or increase the number and function of cytotoxic effectors. Decreased expression of $\mathrm{NFKB}$ in tumor cells in one hand could potentially activate the NK and CTL mediated cytotoxicity resulting in an increased clearance of the tumors by killer effectors. However, lower expression of NFkB in tumors could also potentially generate chronic inflammatory conditions by which untransformed cells could become transformed due to the high levels of inflammatory cytokines induced.

Since tumorigenic and non-tumorigenic human oral keratinocytes acquire sensitivity to NK cell mediated lysis when NFKB is inhibited, it is likely that this phenomenon is not specific to cancer or oral keratinocytes, and it may occur in other healthy non-transformed cell types [15]. Indeed, when human primary monocytes were differentiated to dendritic cells they too became more resistant to NK cell mediated cytotoxicity [15]. Moreover, knock down of COX2 in primary mouse monocytes [15], or in mouse embryonic fibroblasts, resulted in the reversion or de-differentiation of the monocytes and fibroblasts respectively, and the activation of NK cell cytotoxicity. Indeed, it is likely that any disturbance in cellular differentiation may predispose the cells to NK and CTL mediated cytotoxicity. Since STAT3 is an important factor increased during differentiation, blocking STAT3 is also critical in the activation of immune effectors [27]. In support of a critical role of STAT3 in immune evasion of tumor cells in humans, we and others have recently shown that Glioblastoma Multiforme (GBM) tumors display constitutive activation of STAT3 (Cacalano and Jewett, unpublished observation) [30], and poorly induce activating cytokines and tumor-specific cytotoxicity in human Peripheral Blood Mononuclear Cells (PBMCs) and NK cells. Ectopic expression of dominant-negative STAT3 in the GBM cells increased lysis of the tumor cells by the immune effectors and induced production of IFN- $\gamma$ by the interacting immune effectors.

Based on the accumulated evidence thus far we propose that NK cells and potentially CTLs may play a critical role in differentiation of the cells by providing important signals via secreted cytokines as well as direct cell-cell contact. In order to drive differentiation, NK cells and CTLs will have to first receive signals from stem cells or those which have disturbed or defective capabilities to differentiate in order to be conditioned to lose cytotoxicity and gain in cytokine producing phenotype. Indeed, we have previously coined this concept as split anergy in NK cells which is induced by not only sensitive tumor cells but also after triggering of the CD16 receptor [7,20,21,31,32]. In cancer patients since the majority of NK cells and CTLs have lost cytotoxic activity, they may eventually contribute rather than halt the progression of cancer by not only driving the differentiation of tumor cells but more importantly, by allowing the growth and expansion of the pool of cancer stem cells.

\section{References}

1. Veltri RW, Rodman SM, Maxim PE, Baseler MW, Sprinkle PM (1986) Immune complexes, serum proteins, cell-mediated immunity, and immune regulation in patients with squamous cell carcinoma of the head and neck. Cancer 57: 2295-2308.

2. Schantz SP, Shillitoe EJ, Brown B, Campbell B (1986) Natural killer cell activity and head and neck cancer: a clinical assessment. J Natl Cancer Inst 77: 869875

3. Cortesina G, De Stefani A, Giovarelli M, Barioglio MG, Cavallo GP, et al. (1988) Treatment of recurrent squamous cell carcinoma of the head and neck with low doses of interleukin-2 injected perilymphatically. Cancer 62: 2482-2485.

4. Aggarwal S, Pittenger MF (2005) Human mesenchymal stem cells modulate allogeneic immune cell responses. Blood 105: 1815-1822.

5. Selmani Z, Naji A, Zidi I, Favier B, Gaiffe E, et al. (2008) Human leukocyte antigen-G 5 secretion by human mesenchymal stem cells is required to suppress T lymphocyte and natural killer function and to induce CD4+CD25highFOXP3+ regulatory T cells. Stem Cells 26: 212-222.

6. Spaggiari GM, Capobianco A, Abdelrazik H, Becchetti F, Mingari MC, et al. (2008) Mesenchymal stem cells inhibit natural killer-cell proliferation, cytotoxicity, and cytokine production: role of indoleamine 2,3-dioxygenase and prostaglandin E2. Blood 111: 1327-1333.

7. Jewett A, Bonavida B (1996) Target-induced inactivation and cell death by apoptosis in a subset of human NK cells. J Immunol 156: 907-915.

8. Jewett A, Wang MY, Teruel A, Poupak Z, Bostanian Z, et al. (2003) Cytokine dependent inverse regulation of CD54 (ICAM1) and major histocompatibility complex class I antigens by nuclear factor kappaB in HEp2 tumor cell line: effect on the function of natural killer cells. Hum Immunol 64: 505-520. 
Citation: Jewett A, Nakamura H, Wang M, Teruel A, Paranjpe A, et al. (2012) Dedifferentiation of Epithelial Tumors Enhances Cytotoxicity, Survival and Expansion of Allogeneic CD8+ T Cells and Natural Killer Cells. J Carcinogen Mutagen S1:007. doi:10.4172/2157-2518.S1-007

9. Pasparakis M, Courtois G, Hafner M, Schmidt-Supprian M, Nenci A, et al. (2002) TNF-mediated inflammatory skin disease in mice with epidermisspecific deletion of IKK2. Nature 417: 861-866.

10. Berlin AL, Paller AS, Chan LS (2002) Incontinentia pigmenti: a review and update on the molecular basis of pathophysiology. J Am Acad Dermatol 47: 169-187.

11. Seitz CS, Lin Q, Deng H, Khavari PA (1998) Alterations in NF-kappaB function in transgenic epithelial tissue demonstrate a growth inhibitory role for NFkappaB. Proc Natl Acad Sci USA 95: 2307-2312.

12. van Hogerlinden M, Rozell BL, Ahrlund-Richter L, Toftgard R (1999) Squamous cell carcinomas and increased apoptosis in skin with inhibited Rel/nuclear factor-kappaB signaling. Cancer Res 59: 3299-3303.

13. van Hogerlinden M, Rozell BL, ToftgÃ¥rd R, Sundberg JP (2004) Characterization of the progressive skin disease and inflammatory cell infiltrate in mice with inhibited NF-kappaB signaling. J Invest Dermatol 123: 101-108.

14. Karin M, Cao Y, Greten FR, Li ZW (2002) NF-kappaB in cancer: from innocent bystander to major culprit. Nat Rev Cancer 2: 301-310.

15. Tseng HC, Arasteh A, Paranjpe A, Teruel A, Yang W, et al. (2010) Increased lysis of stem cells but not their differentiated cells by natural killer cells; dedifferentiation or reprogramming activates NK cells. PLoS One 5: e11590.

16. Teruel A, Romero M, Cacalano NA, Head C, Jewett A (2008) Potentia contribution of naÃ ve immune effectors to oral tumor resistance: role in synergistic induction of VEGF, IL-6, and IL-8 secretion. Cancer Immunol Immunother 57: 359-366.

17. Rioux S, Begin C, Dubreuil JD, Jacques M (1997) Isolation and characterization of LPS mutants of Actinobacillus pleuropneumoniae serotype 1. Curr Microbiol 35: 139-144

18. Opitz OG, Harada H, Suliman Y, Rhoades B, Sharpless NE, et al. (2002) A mouse model of human oral-esophageal cancer. J Clin Invest 110: 761-769.

19. Jewett A, Arasteh A, Tseng HC, Behel A, Arasteh H, et al. (2010) Strategies to rescue mesenchymal stem cells (MSCs) and dental pulp stem cells (DPSCs) from NK cell mediated cytotoxicity. PLoS One 5: e9874.

20. Jewett A, Cacalano NA, Teruel A, Romero M, Rashedi M, et al. (2006) Inhibition of nuclear factor kappa B (NFkappaB) activity in oral tumor cells prevents depletion of NK cells and increases their functional activation. Cancer Immunol Immunother 55: 1052-1063.
21. Jewett A, Bonavida B (1995) Target-induced anergy of natural killer cytotoxic function is restricted to the NK-target conjugate subset. Cell Immunol 160: 91 97.

22. Lukacher AE (2002) IFN-gamma suspends the killing license of anti-tumor CTLs. J Clin Invest 110: 1407-1409.

23. Malmberg KJ, Levitsky V, Norell H, de Matos CT, Carlsten M, et al. (2002) IFNgamma protects short-term ovarian carcinoma cell lines from CTL lysis via a CD94/NKG2A-dependent mechanism. J Clin Invest 110: 1515-1523.

24. Jewett A, Cacalano NA, Head C, Teruel A (2006) Coengagement of CD16 and CD94 receptors mediates secretion of chemokines and induces apoptotic death of naive natural killer cells. Clin Cancer Res 12: 1994-2003.

25. Thomas GR, Chen Z, Leukinova E, Van Waes C, Wen J (2004) Cytokines IL-1 alpha, IL-6, and GM-CSF constitutively secreted by oral squamous carcinoma induce down-regulation of CD80 costimulatory molecule expression: restoration by interferon gamma. Cancer Immunol Immunother 53: 33-40.

26. Diehl S, Rincon M (2002) The two faces of IL-6 on Th1/Th2 differentiation. Mo Immunol 39: 531-536.

27. Wang T, Niu G, Kortylewski M, Burdelya L, Shain K, et al. (2004) Regulation of the innate and adaptive immune responses by Stat- 3 signaling in tumor cells. Nat Med 10: 48-54.

28. Speiser DE, Pittet MJ, Valmori D, Dunbar R, Rimoldi D, et al. (1999) In vivo expression of natural killer cell inhibitory receptors by human melanomaspecific cytolytic T lymphocytes. J Exp Med 190: 775-782.

29. Paranjpe A, Cacalano NA, Hume WR, Jewett A (2007) N-acetylcysteine protects dental pulp stromal cells from HEMA-induced apoptosis by inducing differentiation of the cells. Free Radic Biol Med 43: 1394-1408.

30. Rahaman SO, Harbor PC, Chernova O, Barnett GH, Vogelbaum MA, et al (2002) Inhibition of constitutively active Stat3 suppresses proliferation and induces apoptosis in glioblastoma multiforme cells. Oncogene 21: 8404-8413.

31. Jewett A, Cavalcanti M, Bonavida B (1997) Pivotal role of endogenous TNFalpha in the induction of functional inactivation and apoptosis in NK cells. $J$ Immunol 159: 4815-4822.

32. Jewett A, Teruel A, Romero M, Head C, Cacalano N (2008) Rapid and potent induction of cell death and loss of NK cell cytotoxicity against oral tumors by $\mathrm{F}\left(\mathrm{ab}^{\prime}\right) 2$ fragment of anti-CD16 antibody. Cancer Immunol Immunother 57 1053-1066.
This article was originally published in a special issue, Stem Cells-Cancer Research handled by Editor(s). Dr. Claudio Luparello, University of Palermo, Italy 